\title{
Processo de Representação e Participação Social: uma análise crítica
}

\author{
Paulo Sérgio Silvino do Nascimento ${ }^{1}$; Hewelanya de Souza Uchôa ${ }^{2}$
}

\begin{abstract}
Resumo: A gestão de bacias hidrográficas assume uma crescente importância no Brasil à medida que aumentam os efeitos de degradação ambiental sobre a disponibilidade de recursos hídricos. Nas regiões hidrográficas, podemos observar tensões entre representação e participação. A participação social se enquadra no processo de redefinição entre o público e o privado, dentro da perspectiva de redistribuir o poder em favor dos sujeitos sociais que geralmente não tem acesso a informação. Desta forma se propõe neste trabalho como objetivo central analisar o processo de representação e participação dos diversos segmentos sociais na gestão do Comitê da SubBacia Hidrográfica do Alto Jaguaribe (CSBHAJ). Como procedimentos metodológicos para a realização da pesquisa, foram utilizados, além dos levantamentos bibliográficos e documentais, a aplicação de entrevistas semiestruturadas e observações sistemáticas. Os resultados demonstraram um elevado grau de concentração da representatividade entre os municípios da sub-bacia, porém, apontando para uma redução desta concentração a partir das alterações nos critérios de eleição para a renovação de nova composição no ano de 2015.
\end{abstract}

Palavras-Chave: Comitê de Bacia Hidrográfica. Alto Jaguaribe. Representação. Participação Social.

\section{Process of representation and social participation: a critical analysis}

\begin{abstract}
Watersheds management is increasingly important in Brazil as they increase the effects of environmental degradation on the availability of water resources. In the river basin, we can see tensions between representation and participation. Social participation fits into the reset process between public and private, within the perspective of redistributing power in favor of social subjects that generally do not have access to information.Thus it is proposed in this work as a central objective to analyze the process of representation and participation of various social groups in the Committee of Management of Hydrographic Sub-Basin Alto Jaguaribe (CSBHAJ). As methodological procedures for the research were used in addition to the bibliographic and documentary surveys, the application of semi-structured interviews and systematic observations. The results showed a high degree of concentration of representation among the municipalities of the sub-basin, however, pointing to a reduction of the concentration from the changes in the eligibility criteria for the renewal of new composition in 2015 .
\end{abstract}

Keywords: Watershed Committee. Alto Jaguaribe. Representation. Social participation.

\section{Introdução}

As práticas participativas na gestão de recursos hídricos marcam a partir da expressão do coletivo, uma nova qualidade de cidadania, que insere o cidadão como criador de direitos para abrir novos espaços de participação, para multiplicar iniciativas de gestão que articulam eficazmente, a complexidade com a democracia.

\footnotetext{
${ }^{1}$ Graduado em Geografia, Mestre em Desenvolvimento Regional, Doutor em Geografia pela UNESP, Rio Claro. Professor do quadro permanente do Instituto Federal de Educação, Ciência e Tecnologia do Ceará, campus Juazeiro do Norte. E-mail: paulosergio.ifce@gmail.com;

${ }^{2}$ Acadêmica de Serviço Social do Instituto Federal de Educação Ciências e Tecnologia do Ceará - IFCE, campus Iguatu. Possui graduação em Licenciatura de Biologia e Química pela Universidade Estadual Vale do Acaraú - UVA (2005) e Especilização em educação ambeintal pela Universidade Regional do Cariri - URCA.
} 
No Brasil foram aprovadas na década de 1990, leis que definiram uma nova organização do sistema de gestão de recursos hídricos rompendo com uma lógica de planejamento centralizado. Isso demanda negociação entre os órgãos dos diferentes níveis de governo, os usuários e a sociedade civil organizada. A negociação e o planejamento são realizados por bacia hidrográfica, através dos colegiados organizados que deliberam sobre as atividades e políticas públicas que possam afetar a quantidade e a qualidade das águas.

A legislação enfatiza a prática de planejamento do uso e conservação dos recursos hídricos determinando a elaboração de planos de bacias hidrográficas e propõe também uma política participativa, um processo decisório, aberto aos diferentes atores sociais vinculados ao uso da água dentro de um contexto mais abrangente de revisão das atribuições do Estado, do papel dos usuários e do próprio uso da água.

A participação social nas decisões das políticas públicas deve ser analisada num contexto social das lutas de classes e da relação de unidade e luta existente na relação entre o

Estado e a Sociedade Civil.

Em relação ao conceito de sociedade civil, Pereira (1995, p. 58), define o conceito de sociedade civil desenvolvido por Marx:

É o verdadeiro centro, o verdadeiro palco da história... Ela abrange o conjunto das relações materiais dos indivíduos no interior de um estágio de desenvolvimento determinado das forças produtivas. Abrange o conjunto da vida comercial e industrial de uma etapa. Assim, a sociedade civil representa o conjunto da estrutura econômica e social de um período determinado.

A participação fortalece a capacidade de crítica e de interveniência dos segmentos mobilizados através de um processo informativo. Entretanto, a composição dos comitês de bacias hidrográficas tem sido objeto de questionamentos, sobretudo pela imprecisão do conceito participação. O termo participativo passou a fazer parte dos discursos governamentais, daí as negociações passaram a ser trabalhadas conjuntamente entre leigos e especialistas.

Assim, a gestão colegiada tende a definir uma dinâmica que permite que os atores integrem e ajustem suas práticas tendo como base uma lógica de negociação que substitui uma concepção tecnocrática visando ajustar interesses e propostas nem sempre convergentes e articulados para um objetivo comum. (GUIVANT; JACOBI, 2003)

Com base nessas informações, esta pesquisa pretende-se também verificar quais desafios têm sido enfrentados pelo CSBHAJ, apresentando sua definição, funcionalidade e características a partir da experiência da Companhia de Gestão dos Recursos Hídricos do Estado do Ceará (COGERH), na implantação da gerência da sub-bacia do Alto Jaguaribe e o seu papel enquanto secretaria executiva do 
respectivo comitê onde foi possível perceber os aspectos essenciais do processo de descentralização da Política Estadual dos Recursos Hídricos (PERH). A partir dessa experiência foi possível realizar uma reflexão e apresentar algumas conclusões que possam servir como informação importante para a gestão da água no ceará e em particular no Alto Jaguaribe, abordando o processo de participação e o envolvimento do CSBHAJ no mesmo.

Este presente trabalho procurou responder as seguintes proposições: (i) como se configura a participação social e a representatividade dos membros do CSBHAJ no âmbito da sub-bacia? (ii) O modelo que vem sendo utilizado nas escolhas/eleição dos seus membros permite assegurar a melhor representatividade na sub-bacia? A dimensão geográfica e as peculiaridades de cada região da subbacia são fatores limitantes na composição proporcional do CSBHAJ? Uma possível subdivisão da sub-bacia do Alto Jaguaribe em microbacias poderia efetivar e fortalecer a participação dos membros do referido Colegiado?

Diante disso, neste artigo, tem-se o objetivo principal de analisar e discutir as diversas composições do CSBHAJ, levando em conta o grau de representação desde o momento de sua formalização aos dias atuais.

\section{Comitês de Bacias Hidrográficas - Órgãos Colegiados na Gestão de Águas do Ceará}

Comitê, do latim committere, significa “confiar, entregar, comunicar”. É o termo empregado para dar significado à comissão, à junta, à delegação, à reunião de pessoas para debate e execução de ação de interesse comum. (MICHAELIS, 2014).

O Comitê de Bacia (CBH) é um órgão colegiado criado pela Lei 11.996/92 e regulamentado pelo decreto 26.462/01, para tal é considerado a necessidade de estabelecer diretrizes para a formação e funcionamento desses colegiados de forma a implementar o Sistema Integrado de Gestão dos Recursos Hídricos - SIGERH, conforme estabelece a Lei Estadual. São órgãos colegiados com atribuições, consultivas e deliberativas, com atuação na bacia ou sub-bacia hidrográfica de sua jurisdição (SRH, 2014a). Atualmente são doze comitês de bacias hidrográficas existentes no Ceará.

A composição desses colegiados se dá por representantes de instituições governamentais e não governamentais distribuída em 04 (quatro) setores: Usuários (30\%); Sociedade Civil (30\%); Poder Público Municipal (20\%); Poder Público Estadual/Federal (20\%). $\quad$ A proporcionalidade entre esses segmentos foi definida pelo Conselho Nacional de Recursos Hídricos, através da resolução n ${ }^{\circ}$ 05, de 10 abril de 2000. Esta norma estabelece diretrizes para formação e funcionamento dos comitês de bacias hidrográficas, representando um avanço na participação da sociedade civil nos comitês. A resolução prevê que os representantes dos usuários sejam $40 \%$ do número total de representantes do 
comitê, que a somatória dos representantes dos governos municipais, estaduais e federal não poderá ultrapassar 40\% e, os da sociedade civil organizada ser no mínimo de 20\%. (BRASIL, 2014)

Segundo a metodologia desenvolvida pela COGERH, para a formação dos comitês, foram definidos três níveis de atuação (Açude, Vale Perenizado, Bacia Hidrográfica) no objetivo de integrar as ações para o Apoio a Organização dos Usuários. De modo geral guiou-se pelas seguintes premissas: respeitar as especificidades de cada realidade enquanto espaço de negociação social com o intuito de resolver eventuais conflitos que venham a ocorrer devido aos múltiplos usos da água; dotar os usuários de informações técnicas para que possam ter uma visão global e integrada da problemática dos recursos hídricos; capacitar os usuários de água nos diversos usos para que estes possam acompanhar as ações governamentais e colaborar com o processo de gestão. Naquela ocasião foram desenvolvidas várias etapas para a formação dos comitês de bacia do Ceará, variando em função da realidade de cada bacia, mas de modo geral seguindo as seguintes etapas: diagnóstico institucional; seminário institucional; encontros municipais, regionais e ou setoriais; comissões municipais de recursos hídricos; congresso de constituição do comitê de bacia; formalização do comitê junto ao Conselho Estadual de Recursos Hídricos - CONERH e reunião de instalação (posse) e eleição da diretoria executiva.

O diagnóstico institucional trata-se de um levantamento das instituições existentes na bacia hidrográfica que possuem potencial para discutir a gestão social da água. Normalmente é feito o cadastro daquelas que se enquadram nos setores definidos pelo Decreto 26.462/2001 e na Resolução do CONERH de $n^{\circ}$ 01/2003, bem como coletando informações sobre os problemas de recursos hídricos na bacia hidrográfica e quais alternativas os informantes têm para solucioná-los. O seminário institucional da bacia é normalmente o primeiro grande evento promovido com o intuito de informar as instituições públicas e a sociedade em geral sobre a política de recursos hídricos (Nacional e Estadual) e sobre o comitê de bacia, além de apresentar um panorama sobre a bacia, coletado a partir do diagnóstico institucional e de estudo técnico realizado pela COGERH. Geralmente neste evento é constituída uma comissão ou um grupo de interessados responsável por articular demais instituições para formação do futuro $\mathrm{CBH}$, é deles também a responsabilidade de planejar as etapas de formação junto com a Secretaria dos Recursos Hídricos - SRH e a COGERH, bem como propor um anteprojeto de regimento interno. Este grupo é normalmente conhecido como Comissão Pró-CBH.

Os comitês de bacias têm seu próprio regimento interno, as assembleias são públicas, somente os membros têm poder de voto, os mandatos de todos os integrantes são de quatro anos, todos os membros podem se candidatar aos cargos da diretoria, esta com mandato de 2 (dois) anos, permitida a recondução por igual período. Os comitês podem criar comissões e câmaras técnicas; a quantidade de membros é variável, devendo apenas obedecer aos percentuais dos quatro setores representados. 
A Lei $\mathrm{n}^{\circ}$ 14.844, de 30 de dezembro de 2010, revoga a Lei ${ }^{\circ} 11.996$, de 24 de julho de 1992, que regia os mesmos componentes, nos primórdios de constituição do aparato legal para os recursos hídricos no Ceará e no contexto desta Lei são competências dos comitês de bacia hidrográfica: I promover o debate de questões relacionadas a recursos hídricos e articular a atuação com entidades interessadas; II - propor a elaboração e aprovar o Plano de Recursos Hídricos da Bacia Hidrográfica; III - arbitrar, em primeira instância administrativa, os conflitos relacionados aos recursos hídricos; IV fornecer subsídios para a elaboração do relatório anual sobre a situação dos recursos hídricos da bacia hidrográfica; V - acompanhar a implementação do plano de recursos hídricos da bacia hidrográfica e sugerir as providências necessárias ao cumprimento de suas metas; VI - propor ao CONERH, critérios e mecanismos a serem utilizados na cobrança pelo uso de recursos hídricos, e sugerir os valores a serem cobrados; VII - estabelecer os critérios para o rateio de custo das obras de uso múltiplo, de interesse comum ou coletivo; VIII - propor ao CONERH programas e projetos a serem executados com recursos oriundos do FUNERH; IX - constituir comissões específicas e câmaras técnicas definindo, no ato de criação, sua composição, atribuições e duração; $\mathrm{X}$ - acompanhar a aplicação dos recursos advindos da cobrança pelo uso dos recursos hídricos; XI - aprovar a proposta de enquadramento de corpos d'água em classes de uso preponderante das Bacias Hidrográficas. (SILVA, 2005).

O Comitê reduz riscos de que o arranjo público seja apropriado por interesses imediatistas, e amplia as possibilidades de uma prática orientada pela negociação. A melhora no acesso à informação e a participação social têm promovido mudanças que favorecem o desenvolvimento de uma consciência coletiva, importante para cidadania. Embora os mecanismos de participação tenham avançado e se institucionalizado, é preciso que se garanta algum poder de decisão nesta representatividade, que sem esta não há de fato a participação.

\section{A Sub-Bacia Hidrográfica do Alto Jaguaribe: Histórico da Gestão Participativa}

O Rio Jaguaribe (jaguar-y-pe), nome originado do tupi-guarani que significa rio das onças, nasce na Serra da Joaninha, no município de Tauá - CE e vai desaguar no Oceano Atlântico, na cidade de Aracati-CE. Compreende boa parte do território cearense, e é dividida em cinco sub-bacias: Alto Jaguaribe, Médio Jaguaribe, Baixo Jaguaribe, sub-bacia Salgado e do Banabuiú. Percorrendo cerca de $610 \mathrm{Km}$ de extensão, da sua nascente até sua foz, abrange cerca de $55 \%$ do território do estado do Ceará, entre as coordenadas $4^{\circ} 30^{\prime}$ e $7^{\circ} 45^{\prime}$ de latitude Sul e $37^{\circ} 30^{\prime}$ e $41^{\circ} 00^{\prime}$ de longitude Oeste. (FUCK JÚNIOR, 2008)

A sub-bacia hidrográfica do Alto Jaguaribe é a segunda maior região hidrográfica do Estado, localizada à montante do açude Orós, drena uma área de $24.636 \mathrm{~km}^{2}$. O rio Jaguaribe, nesta região, 
possui uma extensão aproximada de $325 \mathrm{~km}$, e seus principais afluentes são os rios Carrapateiras, Trici, Puiu, Jucás, Condado, Cariús e Trussu. Os municípios que compõem esta sub-bacia são: Acopiara, Aiuaba, Altaneira, Antonina do Norte, Araripe, Arneiroz, Assaré, Carius, Campos Sales, Catarina, Farias Brito, Icó, Iguatu, Jucás, Nova Olinda, Orós, Parambu, Potengi, Quixelô, Saboeiro, Salitre, Santana do Cariri, Tarrafas e Tauá. (CARTILHA, 2012)

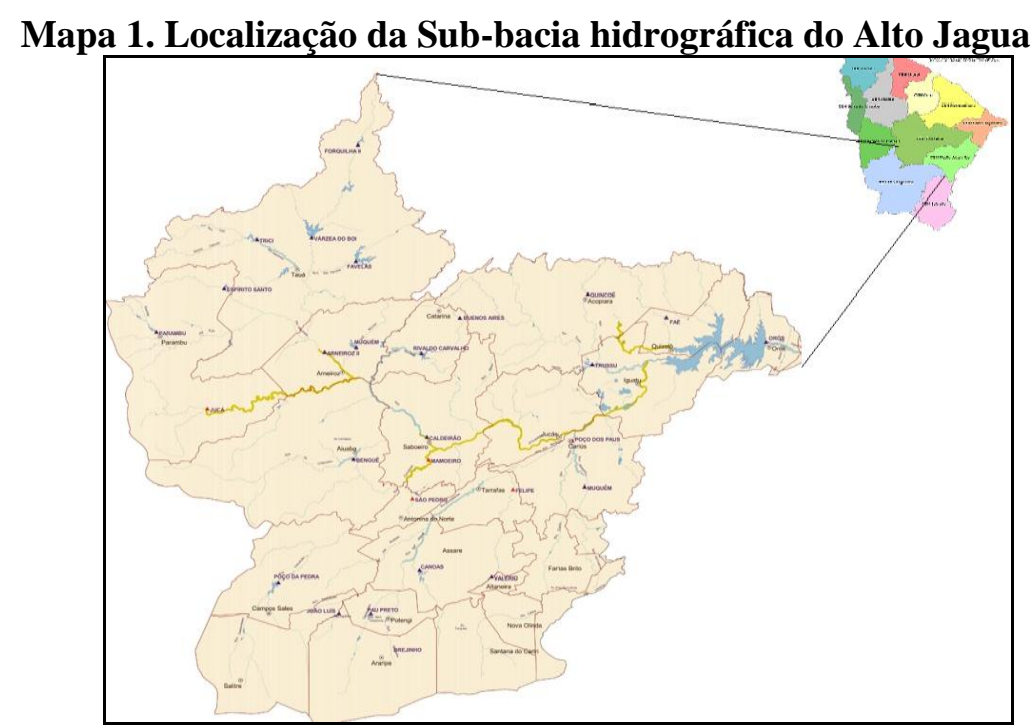

Fonte: Adaptado de COGERH (2015)

Em termos de potencial hídrico a sub-bacia do Alto Jaguaribe acumula cerca de 2,7 bilhões de metros cúbicos. O açude Orós é sua principal reserva hídrica, com a capacidade de acumulação de 1,9 bilhões de metros cúbicos. No total são 24 açudes públicos estratégicos presentes em toda sua extensão, atualmente gerenciados quantitativa e qualitativamente pela COGERH, e entre os principais reservatórios estão: Arneiroz II, Bengue, Canoas, Do Coronel, Faé, Favelas, Forquilha II, Muquem, Mamoeiro, Orós, Parambu, Pau Preto, Poço da Pedra, Quincoé, Rivaldo de Carvalho, Trici, João Luis, Monte Belo, Trussu, Valério e Várzea do Boi (COGERH, 2015).

O trabalho de gestão participativa dos recursos hídricos na sub-bacia do Alto Jaguaribe realizado pela COGERH teve como marco inicial o envolvimento dos seguintes municípios: Quixelô, Iguatu, Orós e Icó. Os representantes destes municípios fizeram parte de uma comissão denominada de comissão de usuários do vale perenizado do rio Jaguaribe conjuntamente com o rio Banabuiú. Esta comissão tinha como objetivo discutir com a COGERH, a gestão das águas naquele vale e redefinir o modelo de gestão. Essa discussão aconteceu no primeiro seminário dos usuários de água dos vales perenizados, no município de Jaguaribe - CE, no mês de julho, no ano de 1994. (SRH, 2014b)

Assim o processo de gestão participativa dos recursos hídricos no Jaguaribe teve início em 1994, quando a COGERH incentivou o processo de gestão da água ao longo dos Vales do Jaguaribe e Banabuiú, formando uma comissão intitulada de Comissão dos Vales. Esta comissão discutia tão somente a operação dos açudes Banabuiú e Orós. Ao longo dos anos a discussão evoluiu para além da 
alocação de água, ou operação dos Vales. Havia um anseio para pautar outros aspectos da gestão dos recursos hídricos como a outorga, a transferência de água, as questões ambientais e entre outras. Para tratar estas questões era necessária a participação dos usuários o que só seria possível por meio dos comitês de bacias previstos em Lei. (CUNHA, 2014)

Porém em virtude da falta de recursos humanos da COGERH, a qual era a articuladora deste processo, devendo atuar em todos os municípios e diante da necessidade de avançar na discussão da gestão da água, ficou acordado com a referida comissão em dividir o Jaguaribe em cinco sub-bacias e assim cada uma teria sua própria comissão. A comissão de usuários do Alto Jaguaribe foi formada tendo como integrantes os representantes de vários setores, porém envolvendo naquele momento apenas os municípios de Icó, Iguatu, Orós e Quixelô. Até 1995 a comissão dos vales contava com 19 dezenove municípios representados nos segmentos de sociedade civil, usuários de água e poderes públicos que definiam o processo de operação dos reservatórios Orós e Banabuiú com o suporte técnico da COGERH. As reuniões desta comissão passaram a ser realizadas de forma itinerante nos municípios localizados nos vales dos rios Jaguaribe e Banabuiú. (CUNHA, 2014)

Em 1995, com o objetivo de iniciar a estruturação do processo de apoio a organização dos usuários das águas em cada uma das bacias hidrográficas que fazem parte do vale do Jaguaribe, reuniões foram realizadas com os representantes de cada bacia hidrográfica, intitulada de reunião das entidades de usuários das águas das bacias do Jaguaribe. A reunião na Bacia do Alto Jaguaribe ocorreu em outubro de 1995, e contou com a participação de 48 representantes. (SRH, 2014b)

Em 1996, a partir de uma avaliação do trabalho na bacia do Jaguaribe, percebeu-se a necessidade de realizar ações no sentido de buscar uma maior articulação no trabalho de organização. Foi então realizado, no início daquele ano, o diagnóstico institucional nos 19 municípios do vale, com o objetivo de identificar as instituições com interesse em recursos hídricos e divulgar a PERH. Nesse mesmo ano, nos meses de maio, junho e julho, foram realizados os encontros municipais em todos os 19 dezenove municípios dos vales perenizados do Jaguaribe e do Banabuiú, (Id. Ibid)

$\mathrm{Na}$ área da sub-bacia do Alto Jaguaribe foram realizados os encontros municipais de Iguatu, Quixelô, Orós e Icó nas respectivas datas: 24 de maio de 1996, 17 de maio de 1996, 14 de junho de 1996 e 04 de julho de 1996. As ações de apoio a organização dos usuários de água nessa região foi inicialmente direcionada para o fortalecimento do processo de alocação participativa. Somente em 1997, após a formação do primeiro comitê de bacia hidrográfica do Ceará ${ }^{1}$, é que o trabalho foi direcionado no sentido de formar os comitês das bacias do Jaguaribe. (Id. Ibid)

O processo de discussão para a constituição do comitê da sub-bacia hidrográfica do Alto Jaguaribe teve como marco a realização da reunião no dia 27 de novembro de 1998 na cidade de Iguatu. Na oportunidade participaram 21 instituições pertencentes aos municípios de Iguatu, Icó,

\footnotetext{
${ }^{1}$ O Comitê de bacia do Curu foi o primeiro instalado no Ceará, a sua criação já tinha sido definida já na Lei 11.996, de 24 de julho de 1992, que dispõe sobre a Política Estadual de Recursos Hídricos, no seu artigo 48[1]. 
Quixelô e Orós. O objetivo desta reunião era preparar os planos de operação dos açudes Lima Campos, Trussu e Orós; envolver a sociedade civil dos municípios que compõem esta sub-bacia na gestão dos recursos hídricos; divulgar a política de água; definir um plano de intervenção na sub-bacia a fim de viabilizar a instalação do comitê e organizar uma comissão de trabalho. Durante este evento foi criada a comissão de usuários da sub-bacia do Alto Jaguaribe, a qual passaria a ser o espaço de interlocução para definir as etapas de formação do comitê. Esta comissão se reuniu por várias vezes, com o intuito de discutir a formação do comitê e também para tratar sobre a operação dos açudes localizados no Alto Jaguaribe. (Id. Ibid)

Em 1999, foi realizado o diagnóstico institucional onde foram visitados todos os municípios que compõe a sub-bacia do Alto Jaguaribe. O objetivo foi de conhecer e contactar as instituições existentes, além de identificar os principais problemas relacionados aos recursos hídricos dos municípios desta sub-bacia. (Id. Ibid)

Na data de 26 de novembro de 1999, no município de Iguatu - CE, foi realizado o I Seminário dos Usuários de Água da sub-bacia do Alto Jaguaribe. O evento teve como objetivo discutir com os 24 municípios desta sub-bacia, as questões relativas a política de recursos hídricos, o papel da COGERH e esclarecer o papel do comitê na gestão participativa das águas. Vale ressaltar que este I Seminário não obteve o êxito desejado, pois não houve a participação de todos os vinte e quatro municípios da sub-bacia. (Id. Ibid)

Neste caso os participantes propuseram como forma de buscar uma maior identidade regional e facilitar a comunicação entre os municípios a divisão da sub-bacia do Alto Jaguaribe em três regiões obedecendo a seguinte distribuição por municípios: Região I - Altaneira, Araripe, Campos Sales, Farias Brito, Nova Olinda, Potengi, Salitre, Santana do Cariri e Tarrafas; Região II - Aiuaba, Antonina do Norte, Arneiroz, Assaré, Parambu, Saboeiro e Tauá e Região III - Acopiara, Carius, Catarina, Icó, Iguatu, Jucás, Orós e Quixelô.

Possivelmente o critério utilizado para compor as três regiões dos encontros citados tenha sido o de proximidade geográfica entre os municípios, uma vez que a sub-bacia do Alto Jaguaribe possui municípios longínquos - fato que dificulta a participação efetiva dos usuários nesta sub-bacia.

Foram realizados três encontros regionais de recursos hídricos, com o objetivo de agregar outras entidades para discutir o processo de gestão, a formação do comitê e preparar o II Seminário dos Usuários de Água nesta sub-bacia. O encontro da região I, foi realizado no dia 27 de abril de 2000, no município de Nova Olinda; O encontro da região II, foi realizado, dia 24 de fevereiro de 2000, no município de Aiuaba; e o encontro da região III, foi realizado dia 26 de outubro de 2000. planejado realizar os encontros regionais no primeiro semestre de 2000, todavia, somente dois encontros aconteceram. O encontro da região III só ocorreu em outubro devido a necessidade de uma paralisação temporária das atividades de formação dos comitês de bacia em função da demanda de atividades voltadas para a alocação de água dos reservatórios do Estado. Salienta-se que essas 
negociações, atualmente, são feitas geralmente de junho a agosto. Após todas as reuniões de operação dos açudes foi definido que o trabalho continuaria paralisado até o término das eleições municipais. Não obstante, a participação expressiva dos representantes municipais nos encontros regionais demonstrou que a estratégia de descentralizar as ações pelas regiões foi bastante exitosa, garantindo uma ampla participação dos diversos setores de usuários de água nas discussões e formulação de propostas para realização do II Seminário da sub-bacia do Alto Jaguaribe. (Id. Ibid)

Em 07 de dezembro de 2000, no município de Assaré, realizou-se o II seminário de planejamento da sub-bacia do Alto Jaguaribe. Este evento foi fruto dos encontros regionais e do anseio dos municípios pela instalação do comitê da sub-bacia do Alto Jaguaribe. O seminário teve como principal objetivo iniciar o processo de formalização do comitê e definir sua instalação. Ressalta-se que este II seminário foi um ponto importante para a formação do comitê, pois a partir dele foram norteadas as atividades que levaram a constituição. (Id. Ibid)

O seminário contou com a presença de diversas entidades, instituições e usuários de 17 municípios da sub-bacia, havendo representação de setores públicos municipais, estaduais e federais, representação da sociedade civil e usuários. As principais definições desse evento foram: organizar o congresso de constituição do comitê em julho de 2001 e o credenciamento para o congresso. Os participantes dos encontros regionais e dos seminários da sub-bacia deixaram a abertura no estatuto para engajar municípios que não participaram das atividades anteriores. Também foi formado um grupo de estudo para elaboração da proposta de estatuto do comitê. (Id. Ibid)

No dia 14 de dezembro de 2001, em Iguatu, foi realizado o Congresso de constituição do comitê, onde foi aprovado o regimento interno e foram eleitos os membros do primeiro mandato. Para esta gestão o comitê foi constituído com 40 membros, com representantes da sociedade civil, usuários, municípios e órgãos públicos estaduais e federais. (Id. Ibid)

Em 21 de janeiro de 2002, foi encaminhada a documentação, assinada por uma comissão paritária, solicitando a instalação e posse do comitê ao CONERH. A reunião de instalação e posse dos membros do comitê da sub-bacia Hidrográfica do Alto Jaguaribe CSBHAJ ocorreu dia 27 de junho de 2002, no município de Iguatu. Na oportunidade também foi eleita e empossada a primeira diretoria executiva do comitê. (Id. Ibid)

Criado pelo Decreto $\mathrm{n}^{\circ} 26.603$, de 14 de maio de 2002 e instalado em 27 de junho do mesmo ano, composto por quarenta membros o CSBHAJ tem a missão de contribuir com a gestão integrada e descentralizada dos recursos hídricos, garantindo a participação da sociedade no processo decisório, buscando o desenvolvimento sustentável da sub-bacia.

A função da secretaria executiva do comitê é exercida pela COGERH, criada pela Lei $\mathrm{n}^{\circ}$ 12.217, de 18 de novembro de 1993 e vinculada a Secretaria de Recursos Hídricos do estado.

A gerência regional da COGERH na sub-bacia do Alto Jaguaribe, localizada no município de Iguatu, foi instalada em outubro de 2002. Esta unidade descentralizada desenvolve ações de operação, 
manutenção e monitoramento dos sistemas hídricos, bem como trabalha a dimensão social com a gestão participativa, apoiando técnica e administrativamente as ações do CSBHAJ.

Dentre as atribuições asseguradas ao comitê de bacia pelo o decreto $\mathrm{N}^{\circ} 26.462 / 2001$, podemos destacar as reuniões realizadas pelo comitê dentro da sub-bacia, elas são realizadas de maneira itinerante ou não, com o intuito de garantir a maior participação dos seus membros. O CSBHAJ se reúne ordinariamente trimestralmente e de maneira extraordinária sempre que se fizer necessário.

Desde sua formalização no ano de 2002 até o presente momento (Agosto de 2015) o CSBHA realizou um total de quarenta e seis reuniões ordinárias e doze extraordinárias. Durante estas reuniões as pautas têm sido bastante diversificada as quais tratam de assuntos relacionados a alocação dos reservatórios, descentralização dos recursos hídricos dentro da bacia para atender o maior número de usuários, a negociação de conflitos pelo uso da água, a participação dos membros em diversos eventos, congressos, seminários, palestras, além da participação em cursos ministrados por outros órgãos.

\section{Materiais e Método}

O presente trabalho possui como objetivo analisar a participação social e representação no CSBHAJ, a fim de verificar se as tomadas de decisões sobre os recursos hídricos na sub-bacia vêm realizada de forma equitativa e democrática, identificando os problemas desse processo.

A abordagem metodológica empregada nesta pesquisa é quantitativa. Ela se fundamenta no pensamento dedutivo; define variáveis de pesquisa e examina as relações entre as mesmas; se atém à medição numérica; tem a pretensão de generalizar os resultados através de amostras representativas. (FREITAS et al., 2000; SAMPIERI et al, 2006)

O tipo de pesquisa a ser empregado foi o levantamento, que é a obtenção de dados ou informações sobre características de um grupo de pessoas, objetivando produzir descrições quantitativas, mediante um instrumento de pesquisa (FREITAS et al., 2000). As técnicas de coleta de dados empregadas serão a análise de documentos do CSBHAJ, como a listagem de seus membros e representantes. Para o levantamento do processo de formação e instalação do comitê foi realizado a partir da análise das atas e outros registros pertencentes a secretaria executiva do Comitê, além da aplicação de entrevistas a servidores da gerência regional da COGERH E SRH do estado do Ceará. Outros dados foram obtidos a partir de observações ao longo de reuniões ordinárias do comitê. $\mathrm{O}$ tratamento dos dados será quantitativo mediante cálculos de frequência das respostas obtidas, empregando porcentagem. 


\section{Resultados}

A participação nos Comitês de Bacia Hidrográfica é garantida em lei, mas será se ela garante a representação efetiva dos diversos segmentos sociais e espaços da bacia hidrográfica? Segundo Jacobi (2008, p. 14) as formas de participação na gestão dos recursos hídricos são ainda muito incipientes, porém apontam para uma "nova qualidade de cidadania, que institui o cidadão como criador de direitos para abrir novos espaços de participação sociopolítica". A representatividade social reforça o significado da publicização das formas de decisão e de consolidação de espaços públicos democráticos. Daí a importância de reforçar o papel e atuação dos comitês de bacias no sentido de estimular o planejamento, a participação social e a tomada de decisões que visem ao uso sustentável dos recursos hídricos e ao interesse comum.

Os espaços dos comitês os representantes de diversos segmentos sociais são os responsáveis por trazer os interesses das suas bases para o processo decisório. Por isso a representação e a capacidade de representar merecem atenção especial.

Representatividade liga-se à ideia daquele que representa politicamente os interesses de um grupo, de uma classe ou de uma nação. Ela se concretiza através da ação, adesão e participação dos representados. O vínculo que liga um representante aos seus representados é a confiança política em geral, uma vez que o representante é muito mais que um gestor. Ele não possui apenas uma atribuição concreta para um determinado assunto. O representante político tem que se colocar diante de assuntos impensados, em circunstâncias novas, e não pode desempenhar bem seu papel se os representados limitam seu âmbito de ação.

$\mathrm{O}$ valor da representatividade pode ser mensurado pela quantidade e pela qualidade da informação e da interlocução regular com os representados, pela condução das ideias, opiniões, vontades e interesses dos mesmos representados, pela intervenção na resolução de problemas e conflitos relacionados com o grupo que representa, pela representação e participação institucional que realiza, e pelas lutas, propostas reivindicativas e negociações coletivas que desenvolve.

Não será objeto deste estudo a abordagem qualitativa da representação dos membros, mas discutir como o CSBHAJ vem ao longo de sua história compondo o seu quadro de representação quanto a participação dos 24 municípios e suas instituições/entidades no âmbito da sub-bacia.

Os 24 municípios da sub-bacia do Alto Jaguaribe pertencem a três das sete mesorregiões do estado do Ceará, assim distribuídos: 37,5\% na mesorregião Sul cearense; 33,3\% na mesorregião Centro-Sul e 29,2\% na mesorregião dos Sertões Cearenses, conforme verificamos no gráfico 01. A gerência regional da COGERH está situada no município do Iguatu, na microrregião do mesmo nome, e pertencente à mesorregião Centro-Sul. Estes dados mostram que não há uma grande disparidade na 
distribuição geográfica dos municípios entre as três mesorregiões da sub-bacia.

\section{Gráfico 01. Distribuição dos municípios na bacia do Alto Jaguaribe}

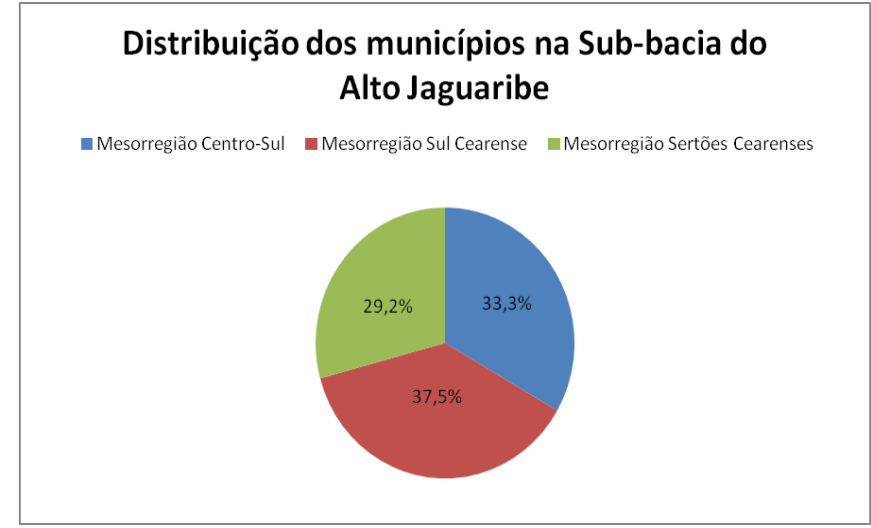

Fonte: Elaborado pelos autores (2015)

A primeira composição do comitê do Alto Jaguaribe tomou posse no dia 27 de junho de 2002 por um período de dois anos, formada por 40 membros que representaram instituições/entidades sediadas em 18 dos 24 municípios, o que corresponde a 75\% dos municípios da sub-bacia. A maioria dos membros que eleitos neste período pertencia a mesorregião Centro-Sul $(52,5 \%)$ e a mesorregião com a menor participação foi a dos Sertões Cearenses (12,5\%), como podemos conferir no gráfico 02.

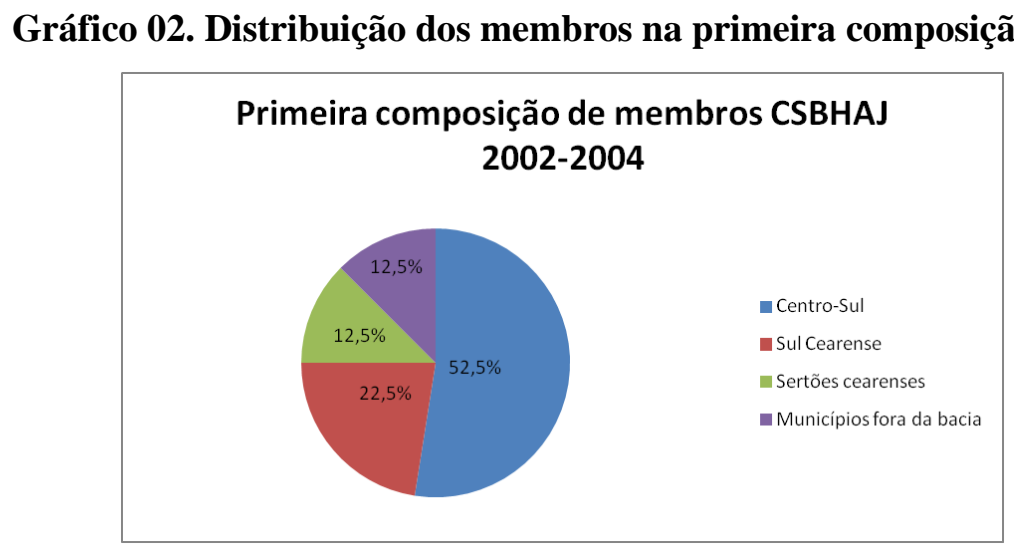

Fonte: Secretaria Executiva do CSBHAL (2015). Org. pelos autores.

A primeira composição de membros do Comitê apresentou uma forte concentração de membros pertencentes a um grupo menor de municípios. Essa concentração é ainda maior quando se percebe que a maioria das instituições representantes pertence a quatro municípios da microrregião do 
$\operatorname{Iguatu}^{2}(45 \%)$ do total. Para completar essa composição, o comitê teve cinco membros $(12,5 \%)$ representantes de instituições federais e estaduais na condição de membros natos ${ }^{3}$ e sediadas em municípios fora da bacia.

A segunda composição do CSBHAJ foi empossada no dia 03 de agosto de 2004, também por um período de dois anos. Dos 40 membros-representantes, 57,5\% representaram a mesorregião Centro-Sul, sendo que $47,5 \%$ do total representaram os municípios da microrregião do Iguatu, conforme se verifica no gráfico 03 .

\section{Gráfico 03. Distribuição dos membros na primeira composição 2004 a 2006}

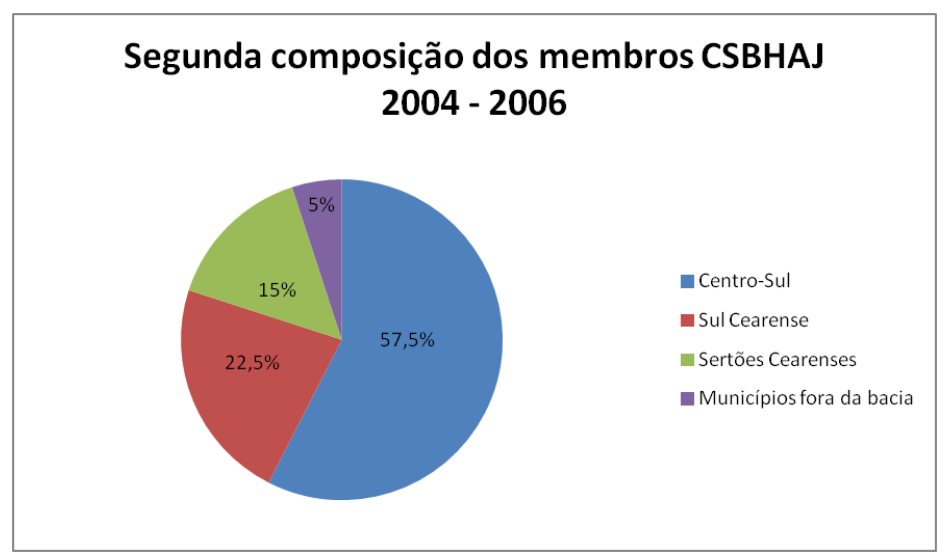

Fonte: Secretaria Executiva do CSBHAL (2015). Org. pelos autores.

A primeira renovação dos membros do comitê mantém a concentração dos membros representantes com o agravante de reduzir o número de municípios representados, passando de $75 \%$ para 70,8\%. A concentração dos membros continuou na Centro-Sul, inclusive com crescimento do número de instituições ligadas aos municípios da microrregião do Iguatu. A mesorregião Sul Cearense mantém a mesma proporcionalidade e um leve incremento da representatividade mesorregião dos Sertões Cearenses passando de $12,5 \%$ para $15 \%$, com a redução do número de membros de municípios de fora da bacia.

Considerando as diversas manifestações feitas pelos comitês de bacias hidrográficas existentes, a Resolução $\mathrm{n}^{\circ}$ 005/2006, de 10 de maio de 2006 altera o prazo dos mandatos dos membros de Comitês de Bacias Hidrográficas de dois para quatro anos. Em 10 de outubro de 2006, representando apenas 13 municípios, ou seja, 54,2\% da sub-bacia, toma posse a terceira composição do CSBHAJ para um mandato de tempo maior.

Para os dois primeiros anos não foi possível completar o total de 40 membros uma vez que

\footnotetext{
${ }^{2}$ A microrregião do Iguatu é parte da mesorregião do Centro-Sul e é formada por cinco municípios: Iguatu, Orós, Icó, Quixelê e Cedro. Destes, apenas o município do Cedro não pertence a sub-bacia dói Alto Jaguaribe.

${ }^{3}$ Conforme o regimento do CSBHAJ são membros natos: A secretaria dos Recursos Hídricos (SRH), Superintendência do Meio Ambiente do estado do Ceará (SEMACE), Instituto Brasileiro dos Meio Ambiente e dos Recursos Naturais Renováveis (IBAMA) e o Departamento de Obras Contra as Secas (DNOCS). 
seis vagas destinadas ao segmento usuários não foram preenchidas. Estas vacâncias somente foram preenchidas em 20 de novembro de 2008, durante o processo de eleição da nova diretoria, o que elevou um pouco a representatividade na sub-bacia, dos 54,2\% para 70,8\% dos municípios.

Da posse até o ano de 2008 o CSBHAJ possuiu o seguinte perfil: 64,7\% representaram instituições da mesorregião do Centro-Sul, sendo 55,9\% do total dos membros pertencentes aos municípios da microrregião do Iguatu; 17,6\% representaram instituições da mesorregião Sul Cearense; 11,8\% representaram os municípios dos Sertões Cearenses; e 5,9\% instituições de municípios de fora da sub-bacia.

Gráfico 04 e 05. Composição dos membros do CSBHAJ no período 2006-20111
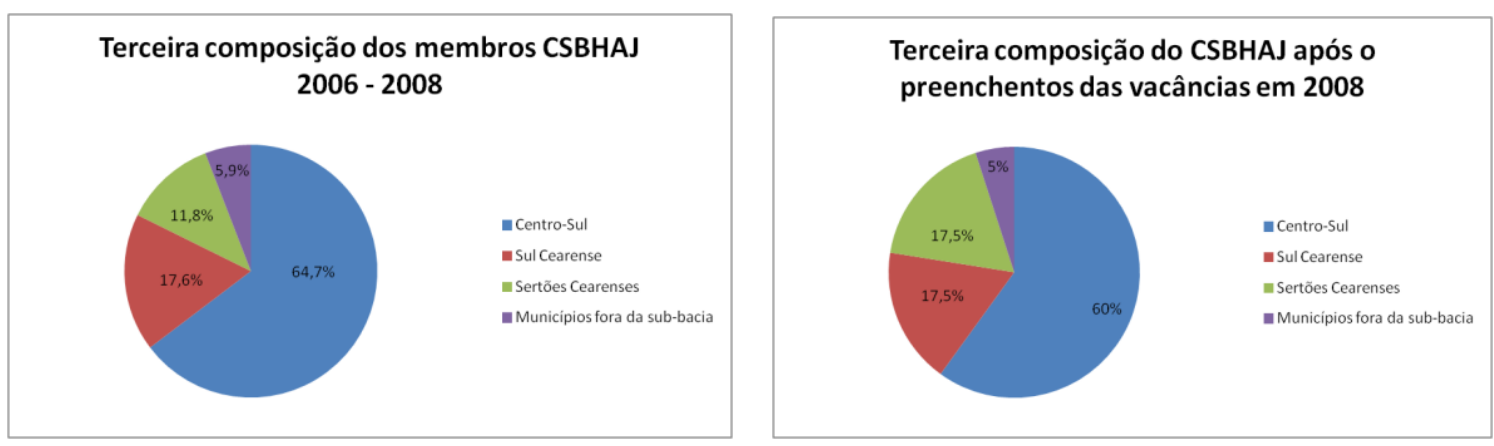

Fonte: Secretaria Executiva do CSBHAL (2015). Org. pelos autores.

Mesmo com a reposição das vacâncias a partir do ano de 2008 o perfil concentrador da composição não sofre importantes alterações, conforme podemos verificar nos gráficos 04 e 05 da figura anterior. Esta composição permaneceu até o primeiro semestre do ano de 2011.

A quarta composição, com uma vacância no segmento do poder público estadual e federal, tomou posse em 20 de abril de 2011. Após documento que altera o mandato dos comitês para 4 anos, o período de renovação seria 2006-2010. Em virtude das eleições municipais o processo de renovação dos membros ocorreu somente em abril de 2011.

Percebe-se a continuidade da forte concentração das instituições-membros dos municípios localizados na mesorregião Centro-Sul com $64,2 \%$, destes $46,2 \%$ representou instituições dos quatro municípios da microrregião do Iguatu. Nesse período a mesorregião dos Sertões Cearenses supera em número de membros a mesorregião Sul Cearense, porém juntas representou apenas 30,8\% do total dos membros do CSBHAJ, como verificamos no gráfico 06. 
Gráfico 06. Distribuição dos membros na primeira composição 2011 a 2015

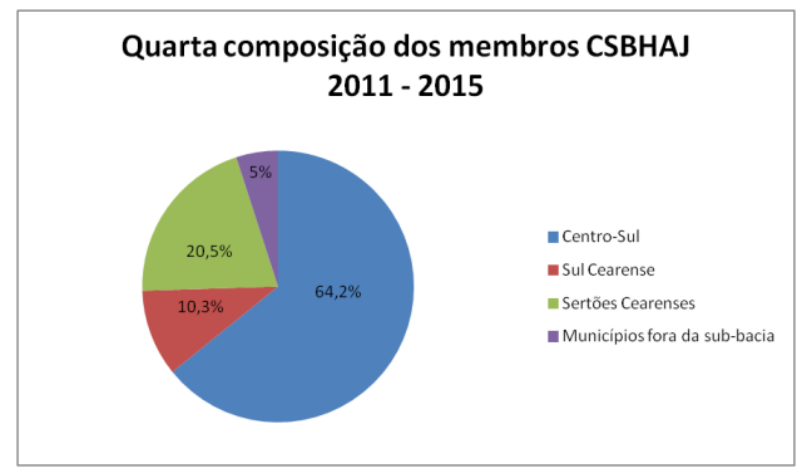

Fonte: Secretaria Executiva do CSBHAL (2015). Org. pelos autores.

Até então a concorrência para a conquista das vagas ocorriam através de disputas entra as instituições de todos os municípios sem a preocupação em regionalizar. Durante a $45^{\circ}$ reunião ordinária do CSBHAJ, realizada na cidade de Iguatu no dia 29 de janeiro de 2015, foram definidos e aprovados novos critérios metodológicos para eleição e renovação dos membros para o mandato 2015-2019. Os membros da comissão coordenadora do processo de renovação do comitê apresentaram o edital e os critérios para renovação 2015-2019 que trouxe a proposta de eleição de forma descentralizada. Todos os municípios da sub-bacia foram distribuídos em quatro grupos obedecendo a proximidade geográfica, e as vagas de cada segmento disputadas em cada grupo. As discussões e as argumentações apresentadas durante a reunião foram no sentido de permitir que o maior número possível de municípios da sub-bacia pudesse envolver os 24 municípios da sub-bacia e assim garantir sua representatividade. Diferente dos critérios utilizados anteriores, a proposta aprovada contemplou uma eleição microrregionalizada. (SECRETARIA EXECUTIVA DO CSBHAJ, 2015)

A mudança na metodologia para a escolha dos membros permitiu compor um comitê menos concentrados, como podemos verificar no gráfico 07.

\section{Gráfico 07. Distribuição dos membros na primeira composição 2015 a 2019}

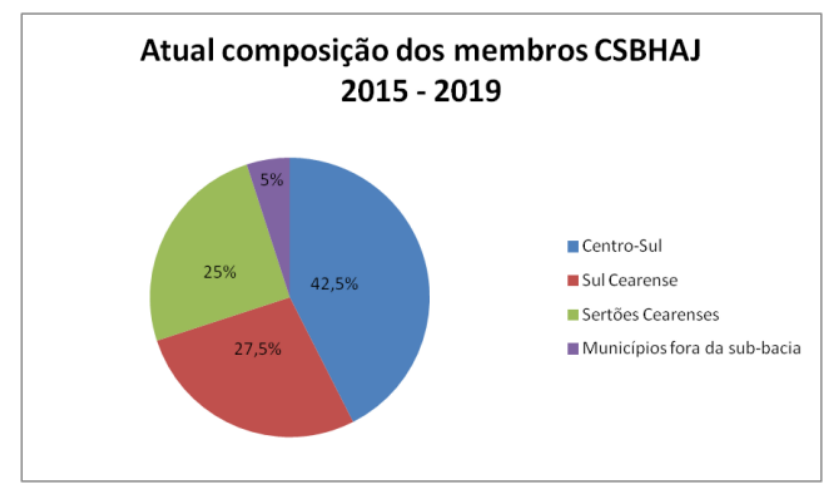

Fonte: Secretaria Executiva do CSBHAL (2015). Org. pelos autores. 
A mesorregião Centro-Sul passou dos $64 \%$ da composição anterior para $42,5 \%$ na atual composição e os municípios da microrregião do Iguatu apresentou o menor percentual desde a instalação do CSBHAJ, consequentemente os municípios das mesorregiões Sul Cearense e Sertões Cearenses passaram a ter maior representatividade.

\section{Considerações Finais}

Verificando o debate atual, a gestão participativa de recursos hídricos tem como espaço privilegiado de discussão e deliberação os comitês de bacias hidrográficas. Porém a definição da bacia hidrográfica como unidade de planejamento da gestão da água, apresenta um desafio considerado de grande proporção em virtude dessa unidade ser definida a partir da realidade física da rede de drenagem da água, não correspondendo aos limites políticos administrativos dos municípios.

Este novo modelo de governabilidade, é entendido como: um processo em que novos caminhos, teóricos e práticos, são propostos e adotados visando estabelecer uma relação alternativa entre o nível governamental e as demandas sociais e gerir os diferentes interesses existentes.

Percebe-se que durante toda a existência deste colegiado a Mesorregião Centro-Sul, especialmente os municípios da microrregião do Iguatu esteve mais representada no colegiado e mais participativa.

Identificamos que as regiões dos Inhamuns e do Cariri oeste (pertencentes as mesorregiões dos Sertões cearenses e Sul Cearenses) também integrantes desta sub-bacia desempenham uma representatividade ainda insuficiente para garantir que a participação abranja toda a região hidrográfica do Alto Jaguaribe.

Observou-se também que a alteração na metodologia do processo de renovação de novos membros aplicadas a partir de 2015 permitiu aumentar a representatividade dos municípios na subbacia.

Durante todo o processo de formalização do comitê vários eventos foram realizados a fim de envolver a sociedade no processo de gestão dos recursos hídricos nesta bacia. Foram identificados diversos problemas relacionados a representação e a representatividade social do Comitê que necessitam ser aprofundados.

Em relação ao grau de representatividade podemos apontar como uma característica desta região hidrográfica, a dificuldade de participação social, embora outros tantos pontos emperram a participação, como a extensão territorial da bacia, a composição da bacia distribuída em 24 municípios longínquos; a falta de recursos financeiros dos membros da sociedade civil para realizar o deslocamento e participar das discussões, sobre isso faz-se necessário a continuidade dos estudos no 
sentido de compreender os aspectos relacionados a participação efetiva das instituições dos diversos segmentos no comitê.

\section{Referências}

BRASIL. Resolução CNRH n ${ }^{\circ}$ 05/2000, de 10/04/2000, modificada pela Resolução no ${ }^{\circ}$, de 20 de dezembro de 2001, e pela Resolução ${ }^{\circ} 24$, de 24 de maio de 2002) Disponível em: http://www.comitepcj.sp.gov.br/Paginas.php?CodPagina=398 Acesso: 25 nov 2014.

MICHAELIS. Dicionário Michaelis. Disponível em: http://michaelis.uol.com.br/escolar/ingles/definicao/portugues-ngles/comite_17124.html

Acesso: 05 dez 2014.

CARTILHA. Comitê da Sub-Bacia Hidrográfica do Alto Jaguaribe. Cartilha Conhecendo as ações do CBH. Iguatu/CE, 1 ed, 24 p. 2012.

COGERH. Companhia de Gestão dos Recursos Hídricos do Ceará. Bacias hidrográficas. Disponível em: http://portal.cogerh.com.br/bacias-hidrografica Acesso: 20 jun 2015.

SECRETARIA EXECUTIVA DO CSBHAJ. Comitê da sub-bacia Hidrográfica do Alto Jaguaribe. In: Ata da $45^{\circ}$ Reunião Ordinária do Comitê da Sub-Bacia Hidrográfica do Alto Jaguaribe. Iguatu, CE, 29 de maio de 2015.

FREITAS, H.; OLIVEIRA, M.; SACCOL, A. Z.; MOSCAROLA, J. O método de pesquisa survey. Revista de Administração, São Paulo, v.35, n.3, jul/set, 2000.

FUCK JÚNIOR, S. C. F. Subsídio à gestão ambiental: descrição fisiografia e análise funcional das bacias hidrográficas do Ceará. Revista Geoambiente, Jataí, n. 10, p. 41-71, 2008.

GUIVANT, J; JACOBI, P. R. Da hidrotécnica à hidropolítica: novos rumos para a regulação e gestão dos riscos ambientais no Brasil. Cadernos de Pesquisa Interdisciplinar em Ciências Humanas. Florianópolis: UFSC, n. 67, 2003.

JACOBI, P. Apresentação. In: RIBEIRO, W. C. Geografia política da água. São Paulo: Annablume, 2008. $162 \mathrm{p}$.

PEREIRA, I. H. A Participação Popular na Gestão Municipal. Fortaleza: UFC, 1995. Dissertação de Mestrado, Faculdade de Educação, 1995, 131p.

SAMPIERI, R. H.; COLLADO, C. F.; LUCIO, P. B. Metodologia de pesquisa. $3^{\text {a }}$ ed. McGraw-Hill, 2006.

SILVA, U. P A. O Histórico de Formação do Comitê da Bacia Hidrográfica do Curu In: XVI Simpósio Brasileiro de Recursos Hídricos, 2005, João Pessoa. Anais do XVI Simpósio Brasileiro de Recursos Hídricos, 2005.

SRH. Secretaria dos Recursos Hídricos do Ceará. Gestão participativa. http://www.srh.ce.gov.br/eixos-de-atuacao/gestao-participativa. Acesso: $10 \mathrm{dez}$ 2014. (2014a) 
Secretaria dos Recursos Hídricos do Ceará. Comitê da Sub-bacia do Alto Jaguaribe. Disponível em: http://www.srh.ce.gov.br/eixos-de-atuacao/gestao-participativa/comites-debacias/comite-da-sub-bacia-hidrografica-do-alto-jaguaribe/historico/ Acesso 20 dez 2014. (2014b)

\section{Entrevista:}

CUNHA. M. A. L. Comitê da sub-bacia do Alto Jaguaribe: depoimento. Fortaleza. Entrevista concedida a Hewelanya de Souza Uchôa, em dezembro de 2014.

\section{Como citar este artigo (Formato ABNT):}

NASCIMENTO, Paulo S.S do;UCHÔA, Hewelanya de S. Processo de Representação e participação Social: Uma análise Crítica. Id on Line Revista de Psicologia, Fevereiro de 2016, vol.,10 n.29. p. 111-128. ISSN 1981-1189.

Recebido: 10/01/2016

Aceito: 18/01/2016 